\title{
The Burden of Power: Construing Power as Responsibility (Rather Than as Opportunity) Alters Threat-Challenge Responses
}

\author{
Annika Scholl', Frank de Wit ${ }^{2}$, Naomi Ellemers ${ }^{3}$, \\ Adam K. Fetterman ${ }^{4}$, Kai Sassenberg, ${ }^{1,5}$, \\ and Daan Scheepers ${ }^{6}$
}

\begin{abstract}
Power usually lowers stress responses. In stressful situations, having high (vs. low) power heightens challenge and lowers threat. Yet, even power-holders may experience threat when becoming aware of the responsibility that accompanies their power. Power-holders can construe (i.e., understand) a high-power position primarily as opportunity to "make things happen" or as responsibility to "take care of things." Power-holders construing power as responsibility (rather than opportunity) may be more likely to experience demands—-such as taking care of important decisions under their control—as outweighing their resources, resulting in less challenge and more threat. Four experiments with subjective and cardiovascular threat-challenge indicators support this. Going beyond prior work on structural aspects (e.g., power instability) that induce stress, we show that merely the way how power-holders construe their power can evoke stress. Specifically, we find that power construed as responsibility (vs. opportunity) is more likely to imply a "burden" for the power-holder.
\end{abstract}

\section{Keywords}

social power, construal of power, threat challenge, biopsychosocial model, cardiovascular stress

Received December 15, 2015; revision accepted January 13, 2018

Individuals often covet positions of power. They try to become captain of their sports team, seek to be group leader, or build their $\mathrm{CV}$ to qualify for management positions. Highpower positions offer access to resources that others depend on (Fiske \& Berdahl, 2007; Keltner, Gruenfeld, \& Anderson, 2003). Power-holders may, thus, feel that they can master any situation (Fast, Gruenfeld, Sivanathan, \& Galinsky, 2009; Scholl \& Sassenberg, 2014). Indeed, power promotes goal-striving (Guinote, 2007b; Keltner et al., 2003), boosts well-being (Kifer, Heller, Perunovic, \& Galinsky, 2013), and lowers stress (Akinola \& Mendes, 2014; Mehta \& Josephs, 2010; Scheepers, de Wit, Ellemers, \& Sassenberg, 2012; Wirth, Welsh, \& Schultheiss, 2006). As such, power can benefit the psychological and physiological functioning of those who possess it.

Yet, at times, the demands to ensure that things go well may weigh heavily on power-holders. Indeed, power-holders often seem at risk for health complaints (Byrne et al., 2014), suggesting that high power can be rather stressful (e.g., Sapolsky, 2005; for summaries, see Galinsky, Rucker, \& Magee, 2015; Sassenberg, Ellemers, Scheepers, \& Scholl,
2014; Sturm \& Antonakis, 2015). The present research argues that the way how power-holders understand, or construe, power plays an important role. When power-holders construe their power as responsibility (rather than as opportunity), they may better realize the demands to be met with their resources, responding with lower functioning. Accordingly, we examined if the construal of power changes threat-challenge responses - as indicators of power-holders' effective functioning in stressful situations (Blascovich, 2008).

\footnotetext{
'Leibniz-Institut für Wissensmedien, Tübingen, Germany

${ }^{2}$ Melbourne Business School, Australia

${ }^{3}$ University of Utrecht, The Netherlands

${ }^{4}$ The University of Texas at El Paso, USA

${ }^{5}$ University of Tübingen, Germany

${ }^{6}$ Leiden University, The Netherlands

Corresponding Author:

Annika Scholl, Leibniz-Institut für Wissensmedien, Schleichstr. 6, D-72076

Tübingen, Germany.

Email: a.scholl@iwm-tuebingen.de
} 


\section{How Social Power Affects Threat and Challenge}

Social power is defined as asymmetric control over one's own and others' valued resources (Fiske \& Berdahl, 2007). Elevated power provides relative independence, whereas low power means that one depends more on power-holders (Fiske \& Berdahl, 2007; Keltner et al., 2003). Power-holders both objectively possess more resources (e.g., information, rewards; Fiske \& Berdahl, 2007; Keltner et al., 2003) and subjectively perceive higher resources to master situations than the powerless; power evokes a sense of control (Scholl $\&$ Sassenberg, 2014), even over uncontrollable outcomes (Fast et al., 2009), and heightens confidence (See, Morrison, Rothman, \& Soll, 2011).

This perception of resources affects how a person responds to (potentially stressful) tasks. Individuals often seek to perform well on tasks, for instance, making budgeting decisions, giving a speech, or solving ability-related tests. Such motivated performance situations imply high demands to fulfill. Individuals, here, evaluate whether they can master the task (Blascovich, 2008; Blascovich \& Tomaka, 1996) by weighing perceived resources (e.g., knowledge, skills) against perceived demands (e.g., task requirements, task effort). The outcome of this evaluation results in threat if demands seem to outweigh resources or in challenge when resources seem to match or exceed demands (Blascovich \& Tomaka, 1996; Tomaka, Blascovich, Kelsey, \& Leitten, 1993).

Threat and challenge imply not only subjective appraisals but also specific patterns of cardiovascular responses while performing the (potentially stressful) task itself (Blascovich $\&$ Tomaka, 1996). Specifically, threat and challenge are evident in changes in total peripheral resistance (TPR; indexing net constriction vs. dilation in the arterial system) and cardiac output ( $\mathrm{CO}$; the amount of blood pumped by the heart). During motivated performance, the heart starts pumping faster (heart rate [HR] increases) and with more force (preejection period [PEP] decreases). In the case of challenge, this cardiac response is coupled with relatively low resistance (TPR) - which allows for the blood to easily flow through the body (CO increases). In the case of threat, this response is coupled with vasoconstriction (higher TPR) which leads to stable, or slightly decreased $\mathrm{CO}$, compared with baseline levels. Challenge, then, implies higher efficiency of the heart in transporting oxygenated blood than threat (Blascovich, 2008; Blascovich \& Tomaka, 1996); it predicts better task performance and health (Blascovich, Seery, Mugridge, Norris, \& Weisbuch, 2004; Scholl, Moeller, Scheepers, Nuerk, \& Sassenberg, 2017; Seery, Weisbuch, Hetenyi, \& Blascovich, 2010).

Previous research established that high (vs. low) power promotes challenge and lowers threat (Akinola \& Mendes, 2014; Scheepers et al., 2012). As previously outlined, powerholders possess and perceive more resources; moreover, power-holders are less focused on demands-for instance, they experience less obstacles (Whitson et al., 2013) and less concern for how others evaluate them than the powerless (Keltner et al., 2003). Accordingly, high-power people should experience a more favorable demands-resources relation-which may explain this more effective challenge response. Yet, high power might not always elicit a stressfree or challenge state. Rather, specific circumstances limit its benefits-such as when power becomes unstable (Sapolsky, 2005; Scheepers, Röell, \& Ellemers, 2015) or a person's status mismatches his or her endocrine profile (Josephs, Sellers, Newman, \& Mehta, 2006). Going beyond such structural or personal circumstances, the way how power-holders construe power may change their level of threat and challenge.

\section{How the Construal of High Power May Alter Threat and Challenge}

By definition, high power is (high) asymmetric outcome control (Fiske \& Berdahl, 2007). This control implies an opportunity, which we define as the possibility and freedom to "make things happen" (e.g., achieving important goals, making final decisions). Moreover, it implies responsibility, which we define as the privilege and inner obligation to "take care of things" (e.g., ensuring that important goals are met; Sassenberg, Ellemers, \& Scheepers, 2012; Sassenberg et al., 2014; for similar definitions, see Fiske \& Berdahl, 2007; Torelli \& Shavitt, 2010). Power-holders usually recognize one of these aspectsthe opportunities or responsibilities. Specifically, they often not only construe power as opportunity, but can also be led to construe power as responsibility (Chen, Lee-Chai, \& Bargh, 2001; De Wit, Scheepers, Ellemers, Sassenberg, \& Scholl, 2017; Scholl, Sassenberg, et al., 2017). Power-holders realizing their responsibility (vs. opportunity) take followers' advice more into account (De Wit et al., 2017) and treat others more considerately (Chen et al., 2001; Gordon \& Chen, 2013; Overbeck \& Park, 2006). Accordingly, power construed as responsibility (vs. opportunity) lowers selfishness and, indirectly, benefits the powerless.

Going beyond these well-known interpersonal implications, we investigate how the construal affects power-holders themselves. Construing power as responsibility may, in fact, entail costs for the power-holder. During motivated performance (e.g., budgeting decisions), a power-holder construing power as opportunity should perceive that he or she can manage demands by means of his or her (high) resources - resulting in high challenge. In contrast, a power-holder construing power as responsibility may realize more demands (e.g., taking care of decisions only he or she can make; ensuring others' well-being) and may perceive resources as being less sufficient to meet these demands-leading to relatively lower challenge. In fact, the challenge response of the latter powerholder may be similar to (though potentially slightly higher than) the response of a low-power person, who generally perceives high demands and low resources (Keltner et al., 2003). 
Accordingly, (only) power-holders construing their power as an opportunity-rather than as a responsibility-should respond with high challenge.

Indeed, initial evidence suggests that power as responsibility might have its "downsides." High power is not always attractive to possess and, especially, less so when construed as responsibility (vs. opportunity; Sassenberg et al., 2012). Following up on this, the present research examines implications for the functioning of those who already possess power. In doing so, we investigate if the way in which powerholders construe power changes their threat-challenge responses, beyond the mere level of power (i.e., high vs. low power; Akinola \& Mendes, 2014; Scheepers et al., 2012).

\section{The Present Research}

We tested our hypotheses in four studies, implementing adaptations of two established power-role manipulations (Experiment 1a and 1b; Guinote, 2007a; Scholl \& Sassenberg, 2014; Weick \& Guinote, 2010), power recall (Experiment 2; Galinsky, Gruenfeld, \& Magee, 2003), and enacted roles with a confederate (Experiment 3 ). To evoke motivated performance, participants anticipated performing investments (Experiment 1a), expected to solve a test (Experiment 1b), or delivered a speech (Experiments 2-3). We assessed threatchallenge responses toward these situations with subjective appraisals (Experiments 1a and $1 \mathrm{~b}$ ) and unobtrusive, realtime cardiovascular indicators (Experiments 2 and 3). As outcomes, we focused on relative challenge - based on the idea that in a concrete situation-evaluating the relation between resources and demands as being more (or less) enough evokes a relative challenge (or threat) state, rather than two independent responses (Blascovich, 2008).

Importantly, we examine construal among those high in power. Accordingly, all studies compared high-power-asresponsibility with high-power-as-opportunity and different control conditions. To empirically substantiate this focus on high power, Experiment 1a tested whether the effects of construal are, indeed, specific to high power or if they also apply to low power. One may define and induce construal among low-power people in at least three different ways - those who, per definition, possess low outcome control (Fiske \& Berdahl, 2007) could either (a) construe their own low power as low responsibility/opportunity, (b) construe their powerholders' (i.e., another person's) power as high responsibility/ opportunity, or (c) construe their own low power as implying still some responsibility/opportunity (though factually possessing relatively low control). As the fairest test inducing construal and power orthogonally and independently, we implemented option (c); this allowed us to show that focusing on one's own opportunities (vs. responsibilities) promotes challenge for those high, but not those low, in power. To compare high-power-as-responsibility with low power in general, Experiments $1 \mathrm{~b}$ and 2 included a standard (neutral) low-power condition. Finally, to test which construal may drive the effect, Experiment 3 included standard high power without reference to opportunity/responsibility.

Ideal sample size was determined prior to data collection to balance statistical power, participant availability, and extensive physiological assessment ( $G *$ Power; Faul, Erdfelder, Lang, \& Buchner, 2007; power $=.80 ; \alpha=.05$; Experiment 1a: estimated small-medium $\operatorname{effect} f=.15$, ideal $n=351$; Experiment 1b: $f=.25, n=128$; Experiments 2, 3: $n=25$ per cell). Due to participant availability and lab capacity, sample size is lower in the studies involving physiological measures. Lab sessions were scheduled for 1 or 2 week(s), after which data collection was completed.

\section{Experiment Ia: Manipulating Power and Construal Orthogonally}

As a first step, we manipulated power and construal orthogonally. This served to test the prediction that construing high power as opportunity, rather than responsibility, heightens challenge - which should not be the case for low power as opportunity (vs. responsibility). For exploratory purposes, we also assessed the demand-resource relation that people experience in the situation at hand. Power-holders (but not the powerless) construing their position as opportunity should perceive that demands can be met with their resources, which should be less so when construing their position as responsibility.

\section{Method}

Participants and design. Three-hundred four participants (211 female, 92 male, one other; $M_{\text {age }}=36.33$ years, $S D=11.92$; range $=18-73)$ completed a $10-$ min online study with a 2 (power: low vs. high) $\times 2$ (construal: opportunity vs. responsibility) between-participants design via prolific. They were randomly assigned to conditions (low-power responsibility: $n=77$, low-power opportunity: $n=77$, high-power responsibility: $n=73$, high-power opportunity: $n=77$ ). In line with our predefined inclusion criteria, which are common in online studies, we excluded 41 additional people; this was done because these people were familiar with our materials (stock investments or manipulations) and, thus, likely aware of their purpose, or because they completed the questionnaire in less than $3 \mathrm{~min}$ (whereas our pretest indicated a duration of about $10 \mathrm{~min}$ ) and, thus, could not have read all instructions. After these exclusions, two additional outliers with studentized residuals greater than $|2.65|$ (i.e., $p<.01$ ) in the main analysis for relative challenge were excluded (see Neter, Kutner, Nachtsheim, \& Wasserman, 1996). The main results are similar but slightly weaker for the whole sample.

Procedure. Participants imagined themselves being in a "business situation," making investments in manager-assistant teams. This setting followed an established procedure to manipulate power and to induce a perception of opportunities 
and/or responsibilities (Scholl \& Sassenberg, 2014). Participants learned that they were working as assistant (low power) or manager (high power) for a well-known investment firm. The firm was about to reinvest a large amount of money in new capital assets. Reinvesting this money was described as an opportunity (e.g., to increase their clients' personal funds and the company's income) or responsibility for their firm (e.g., to secure their clients' retirement savings plans and meet the company's corporate responsibility; see Supplemental Materials for complete instructions).

They read that they would perform two rounds of investment decisions and receive feedback; in fact, these rounds did not take place, but served to create an (anticipated) motivated performance situation that can induce threat/challenge. Following standard power-role manipulations, assistants learned they would check information and provide suggestions (e.g., which stocks to invest in); managers would make final decisions and evaluate the assistant's performance (Scholl \& Sassenberg, 2014; see also, for example, Guinote, 2007a). To make this upcoming task as vivid and real as possible, participants received general information about stock investments (e.g., brief definitions of "market capitalization," "dividend yield," etc.) and performed an individual "practice trial," for which they chose three (out of six available) stocks to invest in.

Then, supposedly before starting the actual investment task together, participants indicated the level of challenge/ threat as well as the demands/resources they perceived at this very moment; they completed a power manipulation check and control measures and were debriefed that the joint investments would not actually take place, thanked, and compensated.

Measures. Unless indicated otherwise, responses were given on 7-point scales $(1=$ strongly disagree/not at all, $7=$ strongly agree/very). Twelve items (six each) assessed challenge and threat toward the upcoming investment task and participants' role (e.g., "I feel a little threatened"; "I am very much up for getting started"). These were adapted from the Stress Appraisal Measure (Peacock \& Wong, 1990; Roesch \& Rowley, 2005). In an exploratory principal components factor analysis, threat and challenge items loaded (with opposite signs) on one single factor, explaining $46.4 \%$ of the variance. Accordingly, after recoding threat items, all items were averaged in a relative challenge index $(\alpha=.89)$.

Two items each assessed the demands and resources perceived when entering the situation participants wrote about (e.g., "How demanding do you expect the task to be?"; "To what extent do you expect to have all the resources you need for this task?"; Mendes, Blascovich, Major, \& Seery, 2001), $r(304)=.71$ and $.47, p \mathrm{~s}<.001$. We assessed these after our main outcomes in order not to potentially interrupt effects on challenge. As indicator of the perceived demand-resource relation, we calculated the difference of resources and demands, similar to the threat-challenge index (TCI; that is,

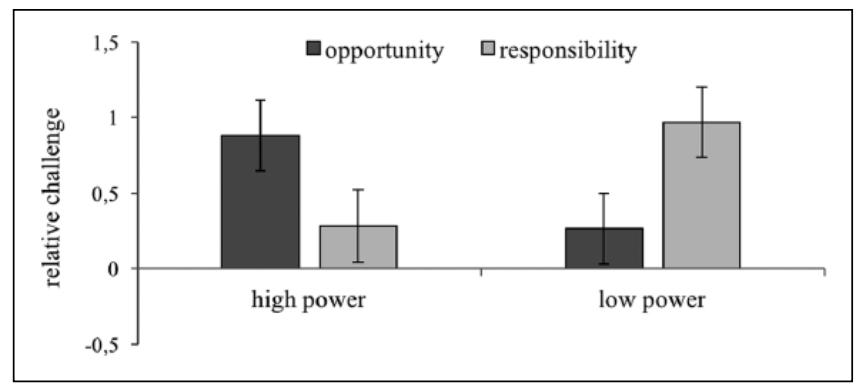

Figure I. Relative challenge ratings (higher values indicate relatively more challenge) as a function of Power $\times$ Construal (Experiment Ia, $n=304$ ).

subtracting demands from resources). As power manipulation check, participants indicated how subjectively powerful they feel at this moment in their role (eight items on 9-point scales; "To what extent do you feel ...," for example, "passive-active," $\alpha=.91$; Smith, Wigboldus, \& Dijksterhuis, 2008).

\section{Results}

Power manipulation check. High-power participants felt more powerful $(M=5.96, S D=1.50)$ than low-power participants $(M=5.44, S D=1.45), F(1,300)=9.06, p=.003, \eta_{p}^{2}=.029$. There was neither a main effect of Construal, $F<1$, nor a Power $\times$ Construal interaction, $F(1,300)=2.07, p=.151$, $\eta_{p}^{2}=.007$. This suggests that our power manipulation was successful and that construal unlikely altered feelings of power.

\section{Main analyses}

Relative challenge. We expected construal as responsibility to induce less challenge than construal as opportunity among those high, but not those low, in power. A 2 (power) $\times 2$ (construal) ANOVA tested this. This analysis yielded no main effect of Power or Construal, $F \mathrm{~s}<1, p \mathrm{~s}>.818$, but the predicted Power $\times$ Construal interaction, $F(1,300)=7.67, p$ $=.006, \eta_{p}^{2}=.025, M D($ mean difference $)=0.652,95 \%$ confidence interval $(\mathrm{CI})=[0.189,1.115]$, indicating a significant reversal of the effect of construal for participants in the low power, compared with the high power, condition.

As predicted, participants in the high-power conditions appeared more challenged under a construal as opportunity $(M=0.88, S D=2.18)$ than construal as responsibility $(M=$ $0.28, S D=1.87), F(1,300)=3.18, p=.075, \eta_{p}^{2}=010$; the reverse was true for low power; here, participants felt less challenged under a construal as opportunity $(M=0.26, S D=$ 1.90) than construal as responsibility $(M=0.97, S D=2.22)$, $F(1,300)=4.56, p=.034, \eta_{p}^{2}=.015$, see Figure 1. Put differently, the construal as opportunity seemed to raise more relative challenge among participants with high power than those with low power, $F(1,300)=3.48, p=.063, \eta_{p}^{2}=.011$, whereas a construal as responsibility raised less challenge 
among participants with high than those with low power, $F(1,300)=4.20, p=.041, \eta_{p}^{2}=.014$.

Moreover, we tested for which conditions participants reported more challenge than threat -in other words, for which conditions our relative challenge measure significantly differed from zero. Within our measure, only participants in the high-power-as-opportunity condition, $t(76)=$ $3.54, p=.001$, but not in the high-power-as-responsibility condition, $t(72)=1.30, p=.200$, reported more challenge than threat. In contrast, only participants in the low-powerresponsibility condition, $t(76)=3.84, p<.001$, but not in the low-power-opportunity condition, $t(76)=1.22, p=.226$, reported more challenge than threat.

We also ran additional exploratory analyses. Note that our main dependent measure, relative challenge, composed of items assessing challenge toward (a) the investment task and (b) participant's role; accordingly, we also ran separate analyses for each of the two challenge subscales (consisting of six items each).

For the subscale Relative Challenge Toward One's Role, there were no main effects, $F_{\mathrm{S}}<1$, but we did again find the expected Power $\times$ Construal interaction, $F(1,300)=7.28$, $p=.007, \eta_{p}^{2}=.024\left(M_{\text {high-power-as-opportunity }}=1.04, S D=2.31\right.$; $M_{\text {high-power-as-responsibility }}=0.52, S D=2.11 ; p=.148 ; M_{\text {low-power- }}$ as-opportunity $=0.46, S D=1.92 ; M_{\text {low-power-as-responsibility }}=1.30, S D$ $=2.45 ; p=.018$ ); here, simple comparisons were more pronounced for those low in power.

Results for the subscale Relative Challenge Toward the Task yielded no main effects, $F \mathrm{~s}<1$, but similar to the previous analyses also showed the predicted Power $\times$ Construal interaction, $F(1,300)=6.64, p=.010, \eta_{p}^{2}=.022$; simple comparisons here were more pronounced for those high in power $\left(M_{\text {high-power-as-opportunity }}=0.72, S D=2.26 ; M_{\text {high-power-as- }}\right.$ responsibility $=0.05, S D=1.83 ; p=.050 ; M_{\text {low-power-as-opportunity }}=$ $0.07, S D=2.08 ; M_{\text {low-power-as-responsibility }}=0.64, S D=2.18 ; p=$ $.094)$. Taken together, these findings supported predictions.

Additional analyses: resources-demands relation. Building upon these findings, we explored if construal as opportunity (vs. responsibility) may promote challenge among high-power (but not low-power) participants because the former may perceive a better demands-resources relation. To do so, we tested for moderated mediation via bootstrapping (Hayes, 2013; Model 7; all predictors centered); Construal served as predictor, the perceived demands-resources relation as mediator, Power as moderator of the path from predictor to mediator, and relative challenge as outcome.

Results supported this model, with an Index of Moderated Mediation of $B=-.71, S E=0.35,95 \% \mathrm{CI}=[-1.435,-0.108]$; Power $\times$ Construal predicted the mediator perceived demands-resources relation, $B=-.87, S E=0.41, p=.034$, $95 \% \mathrm{CI}=[-1.681,-0.068]$, and the mediator predicted the outcome relative challenge, $B=.81, S E=0.05, p<.001,95 \%$ $\mathrm{CI}=[0.715,0.901]$. Importantly, conditional indirect effects indicated that construal as opportunity (vs. responsibility) predicted a better demands-resources relation and, thereby, more challenge only among those high in power, $B=-.60, S E$ $=0.24,95 \% \mathrm{CI}=[-1.12,-0.173]$, not among those low in power, $B=.11, S E=0.24,95 \% \mathrm{CI}=[-0.358,0.628]$. In short, effects were specific to high power.

To conclude, this study yielded first evidence that how people construe a power role differentially affects how challenged they feel toward a potentially stressful situation (here, the investments): High power as opportunity (vs. responsibility) appeared to promote challenge, whereas low power as opportunity (vs. responsibility) produced the opposite. Importantly, this shows that it is the construal of high power (rather than of any role, such as a low-power role) as opportunity, rather than responsibility, resulting in higher challenge. Our additional analyses suggest that these effects may be driven by the perceived demands-resources relation. Yet, as these results are correlational and exploratory, they remain tentative.

\section{Experiment Ib: Construal of High Power, Low Power, and Appraisals}

Building upon Experiment 1a, we implemented even more controlled conditions to rule out demand effects. To do so, we assessed challenge toward an intelligence test that was unrelated to the power role. As Experiment 1a yielded support that our predictions are specific to high power, we implemented a more parsimonious design: the two main conditions highpower-as-responsibility versus high-power-as-opportunity plus one "standard" low-power control condition (without reference to opportunities/responsibilities). We predicted that high-power-as-opportunity evokes more challenge than highpower-as-responsibility and "standard" low power, with the latter two likely not differing from each other.

\section{Method}

Participants and design. One hundred thirty-five undergraduates (96 female; $M_{\text {age }}=24.86$ years, $S D=5.44$; range $=$ 19-61) participated in this experiment, as part of a 1-hr study package, in exchange for $8 €$. Participants were randomly assigned to conditions (standard low power: $n=44$, highpower-as-responsibility: $n=45$, high-power-as-opportunity: $n=46$ ).

Procedure. Participants, up to six at a time, took part in a set of unrelated studies. They received all instructions on screen. First, we induced power via standardized power roles (Guinote, 2007a; Weick \& Guinote, 2010) similar as in Experiment 1a. Participants imagined working in manager-assistant dyads. Their partner was supposedly situated in another room and would later be connected via the computer. After completing a "leadership questionnaire," participants received the manager (high-power-as-opportunity and highpower-as-responsibility) or assistant role (standard low 
power). The manager would instruct and evaluate the assistant; the assistant would contribute solutions.

To reinforce these roles, participants engaged in a rolematching task (Scholl, Sassenberg, Scheepers, Ellemers, \& de Wit, 2017; Weick \& Guinote, 2010). Participants judged another person's ideas in a creativity contest. High-power participants' judgment would contribute to $50 \%$ of the final evaluation determining the winner (i.e., participants did influence another person's outcome). Low-power participants' evaluation was "interesting, but would not determine the winner" (i.e., participants did not influence the other's outcome). Participants saw photographs of five products (e.g., fitness device, perfume bottle) with a product name attached to each, supposedly generated by the other person. They evaluated the innovativeness of each name.

Second, we induced construal in the high-power conditions. Participants learned that they would collaborate with their manager (standard low power) or assistant (both highpower conditions) on a new project. High-power-asopportunity (vs. -responsibility) was induced via the manager's role description. Participants learned that, as the manager, they had the opportunity (vs. responsibility) to instruct the assistant and distribute tasks, were in charge of the assistant's work, and were able to evaluate (vs. will take care of evaluating) the assistant's work. In parallel, low power participants read that as assistant, they would follow the manager's instructions and complete tasks the manager gave to them. The manager would be in charge and evaluate them (see Guinote, 2007a). Participants then completed a power manipulation check and learned that their partner was still engaged in another task. They were asked to proceed to an "unrelated study" while waiting (see Galinsky et al., 2003; Guinote, 2007a). ${ }^{1}$

All participants were then presented with an intelligence test supposedly used in interviews to predict job performance. Participants solved one example item and expected to solve another 20 items within $3 \mathrm{~min}$. This test, in fact, did not take place. It served as standardized motivated performance situation. Participants reported relative challenge regarding this test and were then debriefed.

Measures. Participants responded on 7-point scales $(1=$ strongly disagree to $7=$ strongly agree). Two items assessed perceived power (e.g., "In the upcoming tasks, I will be in charge"), $r(135)=.89, p<.001$. Following Experiment 1a, six items (three items each) assessed challenge and threat regarding the intelligence test (e.g., "I think I can master these tasks"; "I am afraid of not being able to solve the tasks"). Again, these converged on one factor $(59.39 \%$ of variance explained, $\alpha=.86$ ) and were collapsed to indicate relative challenge.

\section{Results}

In this and the following studies, we tested hypotheses with orthogonal contrasts (Abelson \& Prentice, 1997) because all studies fulfilled the criterion of a clear hypothesis allowing for an a priori contrast to be tested. This procedure allows for (a) a focused test of the hypothesis (i.e., by means of one focal contrast) and (b) a test whether any variance is left to be explained (i.e., by the remaining residual contrasts) after removing the variance explained by the focal contrast. This test is more parsimonious, focused, and has greater power (Myers \& Well, 1995; Niedenthal, Brauer, Robin, \& InnesKer, 2002) to detect interaction hypotheses with no classical cross-over pattern, but instead a pattern in which only one condition - in our studies the high-power-as-opportunity condition - is predicted to differ from all the other implemented conditions. With three experimental conditions, we here included one focal contrast (comparing high-power-asopportunity with high-power-as-responsibility and standard low power) and one residual contrast testing potentially unpredicted remaining differences (comparing high-poweras-responsibility with standard low power).

Power manipulation check. Both high-power-as-opportunity $(M=6.26, S D=0.78)$ and high-power-as-responsibility participants $(M=6.02, S D=0.92)$ perceived more power than low-power participants $(M=2.44, S D=0.86)$, focal contrast $\left(\begin{array}{ll}1 & 1\end{array}-2\right): F(1,132)=552.29, p<.001, \eta_{p}^{2}=07$. The highpower conditions did not differ, residual contrast $\left(\begin{array}{lll}1-1 & 0\end{array}\right)$ : $F(1,132)=1.76, p=.186, \eta_{p}^{2}=.013$. Accordingly, the power manipulation was successful. ${ }^{2}$

Relative challenge. We expected high-power-as-opportunity to elicit more challenge than both high-power-as-responsibility and standard low power, captured by the focal contrast $(2-1-1)$. We predicted no differences between high-poweras-responsibility and low power, tested with the residual contrast $\left(\begin{array}{lll}0 & 1 & -1\end{array}\right)$. Indeed, results indicated that high-poweras-opportunity induced more challenge $(M=2.79, S D=$ $2.02)$ than both high-power-as-responsibility $(M=1.33, S D$ $=2.27)$ and low power $(M=1.43, S D=2.25)$, focal contrast: $F(1,132)=12.70, p=.001, \eta_{p}^{2}=088, M D=1.411,95 \% \mathrm{CI}$ $=[0.628,2.195]$. High-power-as-responsibility elicited a similarly (low) level of challenge as low power, residual contrast: $F<1, p=.819$ (Figure 2).

\section{Discussion of Experiments $I a$ and $I b$}

Experiments 1a and $1 \mathrm{~b}$ yielded consistent evidence that high (compared with low) power can heighten challenge-but only when power-holders construe power as opportunity (not responsibility). Participants in both high-power conditions did perceive high power. However, power-holders construing power as responsibility reported lower challenge than those construing power as opportunity. In fact, power-holders construing power as responsibility showed a response similar to those having ("standard") low power (Experiment 1b). Experiment 1a further showed that these effects are specific to construal of high (rather than low) power. Taken 


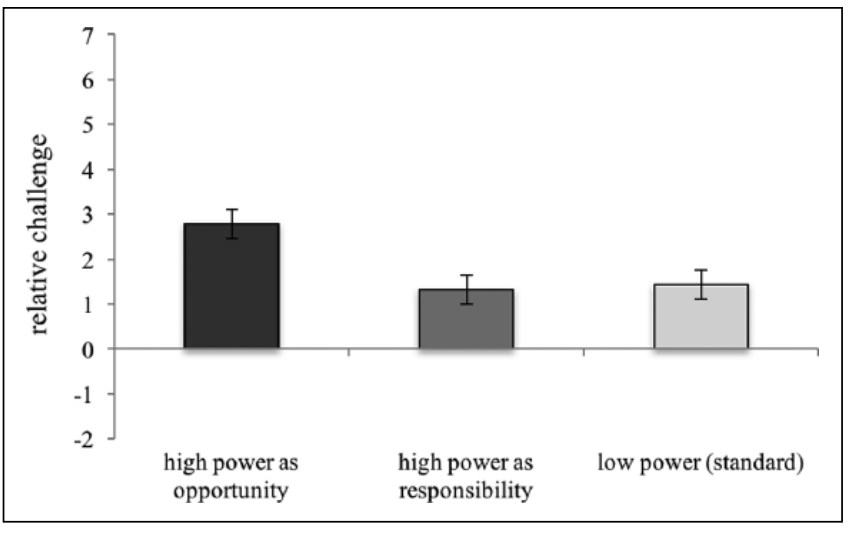

Figure 2. Relative challenge ratings (higher values indicate relatively more challenge) as a function of Power and Construal of high power (Experiment Ib, $n=135$ ).

together, this demonstrates that simply construing high power differently can alter how challenging a (potentially straining) situation appears.

As strengths, these studies relied on highly controlled power roles, supporting the internal validity of findings. Experiment 1a yielded initial evidence that perceptions of resources as sufficing to meet demands may drive the effects. Yet, as our results here were correlational and exploratory, this calls for a more direct test. Future research could aim at compensating effects of high-power-asresponsibility, for instance, by independently inducing high resources/low demands - in which case, the effects of construal as responsibility (vs. opportunity) on challenge should disappear.

As a potential limitation, both studies assessed threatchallenge appraisals as valid, but subjective indicators. Extending this to objective indicators, with potential implications for health, Experiments 2 and 3 assessed physiological responses (Blascovich, 2008; Seery et al., 2010) to more realistic power roles. Again, we implemented the two crucial conditions high-power-as-responsibility versus high-poweras-opportunity. Each study included an additional "standard" low- or high-power condition, respectively. This served as a more practical approach for these studies with extensive physiological testing and enabled us to directly relate our results to earlier findings how "standard" low power versus high power affects physiological responses (Akinola \& Mendes, 2014; Scheepers et al., 2012).

\section{Experiment 2: Construal of High Power and Cardiovascular Responses}

We here relied on real-life power experiences to promote external validity. To assess physiological indicators of threat and challenge, participants "relived" a past experience by delivering a speech to a webcam (Scheepers et al., 2012). We hypothesized that high-power-as-opportunity will evoke a stronger physiological pattern indicative of challenge than high-power-as-responsibility and standard low power.

\section{Method}

Participants and design. Eighty-one undergraduates (70 female; $M_{\text {age }}=19.48$ years, $S D=2.09$; range $\left.=17-28\right)$ participated in exchange for course credit or $4 €$. Participants were randomly assigned to conditions (standard low power: $n=30$, high-power-as-responsibility: $n=26$, high-power-asopportunity: $n=25)^{3}$

Procedure. Participants, up to two at a time in separate cubicles, took part in a 30-min experiment with continuous physiological measurements. They received all instructions and measures on screen. First, the experimenter attached sensors for cardiovascular recording. Second, we recorded baseline cardiovascular measures for $5 \mathrm{~min}$, during which participants sat quietly and watched a neutral movie.

Third, we induced power and construal of high power; participants recalled and relived a personal experience related to power (Galinsky et al., 2003). Low-power participants recalled an incident in which someone had power over them (i.e., control over something they wanted, with no reference to responsibility or opportunity). High-power participants recalled an incident in which they had power (i.e., controlled the ability of another person/persons to get something they wanted, or were in a position to evaluate them; see Galinsky et al., 2003). All participants received the identical (low vs. high) power definition. To induce construal in the high-power conditions, high-power-as-responsibility (vs. -opportunity) participants were asked to recall a situation in which that power had meant being responsible for making decisions and pursuing important goals (vs. had implied an opportunity to do so).

Fourth, participants prepared a speech about how they had felt, what had happened, and how they had handled this situation (Scheepers et al., 2012). To give participants sufficient time to recall their experience, this speech preparation period could take at least $1 \mathrm{~min}$ up to $3 \mathrm{~min}(M=101.93 \mathrm{~s}, S D=$ 38.32). Afterward, participants delivered this speech to the webcam, also lasting $1 \mathrm{~min}$ up to $3 \mathrm{~min}$. During the speech, we recorded (changes in) cardiovascular measures. Finally, participants completed checks and control measures.

Measures. Our primary measures comprised cardiovascular reactivity during the speech, compared with baseline. Physiological measures were recorded noninvasively (Sherwood et al., 1990). A Biopac MP150 system (Biopac Systems In., Goleta, CA) continuously recorded impedance-cardiographic (ICG) and electro-cardiographic (ECG) signals. A Nexfin ${ }^{\circledR}$ BMEYE monitor, a continuous beat-to-beat blood pressure monitor making use of a finger cuff and the volume clamp method, measured blood pressure on the nondominant hand. This monitor has been validated against readings obtained 
with auscultatory measurements (Riva-Rocci/Korotkoff; Eeftinck Schattenkerk et al., 2009). Data were stored and scored using Acqknowledge 4.3.1 software.

Cardiovascular indicators. In line with common practice, CO, TPR, and a TCI, combining CO and TPR in one single, reliable indicator (Blascovich et al., 2004; Mendes, Blascovich, Hunter, Lickel, \& Jost, 2007; Scheepers et al., 2012) served as indicators of threat and challenge. HR and PEP served as indicators of task engagement qualifying the speech as motivated performance.

Checks regarding speeches. Recording speeches enabled us to run checks about the recalled situations. One rater blind to condition coded speech behavior and context features of the recalled situation. The rater rated (a) power context (e.g., family, education), (b) coded power (how much power participants possessed in the situation), (c) evidence of experimental condition (which condition the rater suspected participants to be in), and (d) coded responsibility/opportunity (how much participants expressed responsibilities/ opportunities, respectively; $1=$ very low to $7=$ very high). A second rater coded $10 \%$ of the speeches to validate the first rater's coding_interrater agreement: .61 $<r(9)<.82, \chi^{2}(9)$ $=21.00, p=.013$.

Manipulation checks. Responses were given using 7-point scales $(1=$ not at all to $7=$ completely $)$. Two items assessed perceived power (e.g., "I was in charge in this situation"), $r(81)=.80, p<.001$. Four items each measured perceived responsibility (e.g., "I was responsible for achieving important goals," $\alpha=.81$ ) and perceived opportunity (e.g., "I had opportunities to achieve important goals," $\alpha=.71){ }^{4}$

Perceived (subjective) power and externally coded (objective) power theoretically represent the same construct and were highly correlated, $r(80)=.91, p<.001$. Hence, these were $z$-standardized and collapsed into one score. The same applies to perceived and coded responsibility/opportunity, respectively, $r_{\text {responsibility }}(80)=.62, r_{\text {opportunity }}=.40, p \mathrm{~s}<.001$. Accordingly, both opportunity indicators and both responsibility indicators (all $z$-standardized) were combined into an opportunity check and a responsibility check.

\section{Results}

Checks regarding speeches. Recalled situations ranged from family (32\%), education (25\%), sports (23\%), to work (20\%) and were unaffected by condition, $\chi^{2}(6)=7.54, p=.274$. As a first substantiation of the success of our manipulations, the rater correctly categorized $86 \%$ of the speeches to the three experimental conditions, $\chi^{2}(4)=104.44, p<.001$.

Power check. High-power-as-opportunity $(M=0.73, S E=$ $0.05)$ and high-power-as-responsibility participants $(M=$ $0.72, S E=0.05$ ) expressed more power than low-power participants $(M=-1.22, S E=0.05)$, focal contrast $\left(\begin{array}{lll}1 & 1 & -2\end{array}\right)$ : $F(1,77)=1173.34, p<.001, \eta_{p}^{2}=.938$. Expressed power did not differ between high-power conditions, residual contrast $(1-10): F<1, p=.842$. Separate analyses for these two measures yielded the same findings. Hence, as intended, expressed power differed for low versus high power, but was equal in the two high-power conditions. ${ }^{5}$

Construal check. High-power-as-responsibility participants expressed more responsibility $(M=0.83, S E=0.11)$ than high-power-as-opportunity participants $(M=0.21, S E=$ $0.11)$ and low-power participants $(M=-0.89, S E=0.10)$, focal contrast $(11-2): F(1,77)=129.56, p<.001, \eta_{p}^{2}=$ .627 , and residual contrast $(-110): F(1,77)=16.33, p<$ $.001, \eta_{p}^{2}=.175$.

Expressed opportunity was highest for high-power-asopportunity $(M=0.79, S E=0.12)$, followed by high-poweras-responsibility $(M=0.09, S E=0.11)$, and lowest for low-power participants $(M=-0.71, S E=0.11)$, focal contrast $(11-2): F(1,77)=75.13, p<.001, \eta_{p}^{2}=.494$, and residual contrast $(1-10): F(1,77)=18.40, p<.001, \eta_{p}^{2}=$ .193. Separate analyses for self-ratings and external coding yielded similar patterns. Accordingly, participants followed instructions, and manipulations were both subjectively and objectively successful.

Cardiovascular reactivity checks. Following standard practice, we calculated mean scores for HR, PEP, CO, and TPR for the last minute of the baseline and the first minute of the speech (Scheepers et al., 2012; Seery et al., 2010; see descriptive statistics in Supplemental Material). Reactivity scores were calculated by subtracting baseline scores from speech scores. We checked data for outliers below or above $3.3 S D$ s of the mean. Three outliers were identified. Thorough data checks ruled out that these are due to measurement errors. Hence, we followed the standard procedure and replaced outliers with the next higher (nonoutlying) value of the sample (Scheepers et al., 2012; Weisbuch-Remington, Mendes, Seery, \& Blascovich, 2005). Note that our main results including the original values remain the same or become even stronger (for TCI, outliers work in favor of the hypothesis). As more conservative test, we used the procedure described here.

For the TCI, we subtracted $z$-scored TPR reactivity from $z$-scored CO reactivity (Scheepers et al., 2012; Seery et al., 2010). This index represents relative threat-challenge in a single, more reliable index (Seery et al., 2010). Higher values signal more efficient blood transportation, a motivational state indicative of relative challenge.

Task engagement. A prerequisite for threat and challenge is that the task is engaging (Blascovich, 2008). This implies an increase in HR and a decrease in PEP from baseline to speech (i.e., reactivity scores being different from 0 ). Indeed, HR reactivity increased from baseline to speech, $t(80)$ 
$=14.81, p<.001, M D=18.49,95 \% \mathrm{CI}=[16.00,20.97]$, whereas PEP reactivity decreased, $t(80)=-11.08, p<.001$, $M D=-15.24,95 \% \mathrm{CI}=[-17.98,-12.51]$.

We also tested the general tendency toward challenge or threat. Across conditions, there was a general tendency toward challenge - as indicated by an overall increase in $\mathrm{CO}$, $t(80)=3.54, p=.001, M D=0.89,95 \% \mathrm{CI}=[0.39,1.39]$, and decrease in TPR, $t(80)=-3.19, p=.002, M D=-371.54$, 95\% CI $=[-603.02,-140.06]$ (see tables in Supplemental Material).

Together, this indicates that our speech task constituted motivated performance and created an overall challenge tendency. In other words, all participants were well able to deliver the speech, even though it concerned a personal memory that was, by the time itself, likely demanding. This overall tendency may have been due to the way our speech task was designed. By providing some flexibility in speech preparation time, participants may already have come to regulate some threat away (e.g., they might not have started unless they felt relatively "good" about the situation they were about to explain). Descriptively, preparation time was related to more relative challenge- a higher TCI; $r(81)=$ $.16, p=.155$. To control for this, we controlled for speech preparation time, unaffected by condition, $F(2,78)=1.43, p$ $=.246$, in our main analyses. Note that, despite this overall challenge pattern, it is still possible to test our hypothesisthat high-power-as-responsibility and low power result in relatively less challenge than high-power-as-opportunity.

Cardiovascular threat and challenge. We predicted that compared with high-power-as-opportunity, high-power-asresponsibility (and low power) would evoke less challenge. That is, the latter two conditions would result in relatively lower CO reactivity, higher TPR reactivity, and lower relative challenge (TCI). As before, we tested this with orthogonal contrasts (Abelson \& Prentice, 1997) controlling for speech preparation time. For this purpose, we included the focal contrast $(2-1-1)$ and the residual contrast $\left(\begin{array}{lll}0 & 1 & -1\end{array}\right)$.

Supporting our hypothesis, $C O$ reactivity was higher for high-power-as-opportunity $(M=1.16, S E=0.21)$ and highpower-as-responsibility $(M=0.55, S E=0.20)$ than for low power $(M=0.51, S E=0.19)$, focal contrast: $F(1,77)=6.51$, $p=.013, \eta_{p}^{2}=.078, M D=0.630,95 \% \mathrm{CI}=[0.138,1.122]$. High-power-as-responsibility and low power did not differ, residual contrast: $F<1, p=.904$ (Figure 3). ${ }^{6}$ Analyses yielded no differences between conditions for TPR reactivity $\left(M_{\text {opportunity }}=-499.50, S E=165.19 ; M_{\text {responsibility }}=-407.28\right.$, $\left.S E=160.76 ; M_{\text {low power }}=-366.71, S E=151.08\right)$, focal contrast: $F<1, p=.574$, and residual contrast: $F<1, p=.855$.

As expected, high-power-as-opportunity $(M=0.51, S E=$ 0.32 ) tended to evoke more relative challenge than highpower-as-responsibility $(M=-0.18, S E=0.31)$ and low power $(M=-0.27, S E=0.29)$, focal contrast: $F(1,77)=$ $3.65, p=.060, \eta_{p}^{2}=.045, M D=0.737,95 \% \mathrm{CI}=[-0.032$, 1.505]. High-power-as-responsibility and low power did not

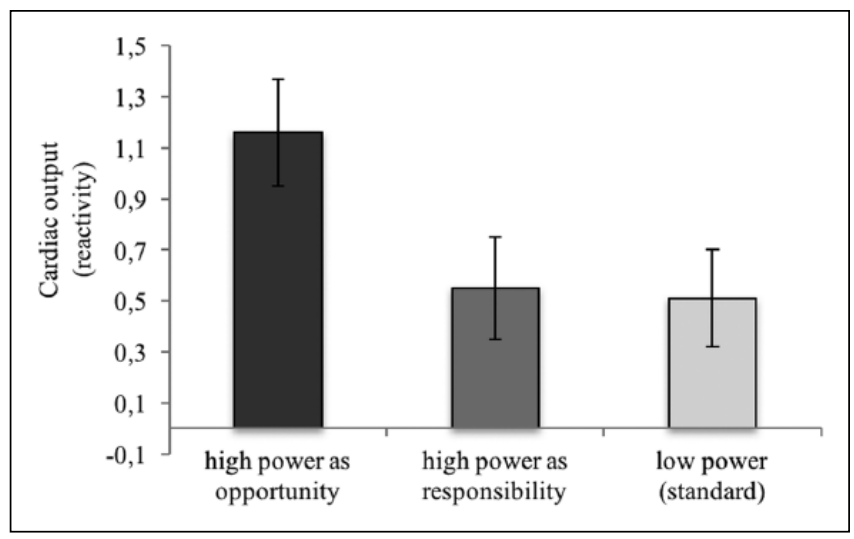

Figure 3. Cardiac output reactivity (changes for speech over baseline; controlling for speech preparation time) as a function of Power and Construal of high power (Experiment 2, $n=8 \mathrm{I}$ ).

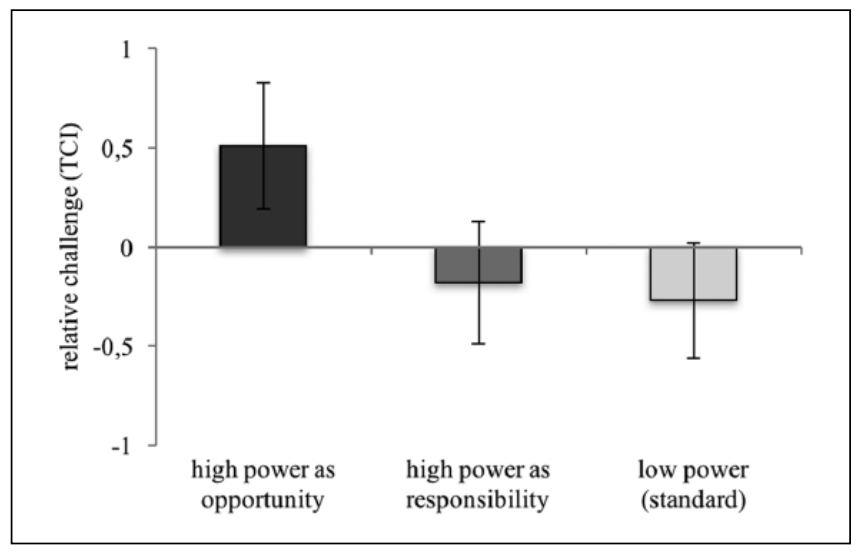

Figure 4. Relative challenge (higher values indicate relatively more challenge and lower values indicate relatively more threat; controlling for speech preparation time) as a function of Power and Construal of high power (Experiment 2, $n=8 \mathrm{I}$ ).

Note. $\mathrm{TCl}=$ threat-challenge index.

differ, residual contrast: $F<1, p=.849$ (Figure 4). Accordingly, results supported our hypothesis for $\mathrm{CO}$ and (marginally) for TCI.

\section{Discussion}

Experiment 2 was the first to examine how high-power-asopportunity, compared with high-power-as-responsibility and low power, predicts physiological threat-challenge indicators. High power did promote greater challenge when it is construed as opportunity, rather than as responsibility (and compared with low power). The findings corroborate and extend our previous studies by showing changes in cardiac performance, here regarding threat-challenge responses to real experiences from various power contexts.

Notably, however, our results need to be treated with some caution. First, participants overall seemed challenged (not threatened). Despite the advantages of recalling real-life 
experiences, this may have been caused by the way our speech task was designed, as suggested by results being stronger when controlling for preparation time. To ensure the robustness of findings, we sought to replicate this in a follow-up study with a more standardized induction of construal before giving a speech about an identical situation.

Second, we compared construal of high power either with standard low power (Experiments $1 \mathrm{~b}$ and 2) or with construal of low power (Experiment 1a). To extend this, Experiment 3 examined which construal among power-holders may drive the effect by including a neutral high-power condition.

\section{Experiment 3: Construal, Standard High Power, and Cardiovascular Responses}

This study compared high-power-as-opportunity and highpower-as-responsibility with standard high power - the latter inducing no specific construal of power. This allowed us to examine whether opportunity represents the likely "default" construal, while additional demands may come into play when high power is construed as responsibility. The experiment implemented a role-playing exercise with a confederate to create a vivid, but controlled context in which all participants delivered a speech about an identical task. We predicted that high-power-as-opportunity would elicit more challenge than high-power-as-responsibility - and, potentially, similar to standard high power.

\section{Method}

Participants and design. Fifty-four undergraduates (45 female; $M_{\text {age }}=20.91$ years, $S D=2.40$; range $=18-27$ ) participated in exchange for course credit or $10 €$. Participants were randomly assigned to conditions (responsibility: $n=19$; opportunity: $n=22$; standard: $n=13)^{7}$

Procedure. Two people at a time completed a study on "team decision-making." In fact, one person was the actual participant, the other a confederate. The role-play served to induce high power and manipulate construal. Upon arrival, each participant was introduced to the confederate and seated in a private cubicle in front of a computer equipped with a web camera.

Following Experiment 2, we measured cardiovascular responses with the same indicators between baseline (last 3 $\mathrm{min}$ ) and speech. After baseline measurements, all participants received high power in a decision-making task. Participants learned that they would form a team with "the other participant." Their team would solve a number of tasks, with the best performing team earning a $25 €$ bonus. One member would be the "captain," the other the "advisor." Participants completed an individual estimation task (estimating the correct number of marbles in two vases), supposedly to assign them to their role. In fact, all participants were the "captain" (high-power role). The confederate always was the "advisor" (low-power role).

The captain's role description induced construal. Highpower-as-opportunity (vs. -responsibility) participants read that, as team captain, they had the opportunity (vs. responsibility) to determine the final team decision and were able to determine how the bonus is distributed (vs. responsible for distributing the bonus). In parallel, participants in the standard high-power condition read that, as team captain, they determine the final answer for the team and distribute the possible bonus. This followed the standard procedure to induce "default" high power (Galinsky et al., 2003; Guinote, 2007a, 2007b) without reference to opportunities/responsibilities.

We then created a motivated performance situation. First, participants solved three estimation tasks individually (e.g., estimating the costs of an all-inclusive holiday) within a maximum of 3 min per estimation. Second, they delivered a speech in the webcam about their estimations (lasting at least $1 \mathrm{~min}$ up to $3 \mathrm{~min}$ ). The speech was recorded and presented to the "advisor," who would respond to their estimations. Participants then completed an advice-taking task unrelated to the current research (these results are reported in De Wit et al., 2017), as well as checks and control questions.

Measures. Reactivity scores from baseline to speech for HR, PEP, CO, and TPR were, again, our primary indicators. We also assessed perceived power with two items (Anderson \& Galinsky, 2006; 1 = strongly disagree to $7=$ strongly agree), $r(54)=.45, p=.001$.

\section{Results}

Power check. Perceived power was higher than the midpoint (i.e., 4) of the scale $(M=5.13, S E=0.16), t(53)=$ $7.19, p<.001$. Accordingly, all participants experienced high power and reported the same level of power across conditions $\left(M_{\text {opportunity }}=5.36, S E=0.25 ; M_{\text {responsibility }}=\right.$ 5.03, $\left.S E=0.27 ; M_{\text {standard }}=4.89, S E=0.32\right)$, focal contrast $(1-21): p=.771$, and residual contrast $\left(\begin{array}{lll}-1 & 0 & 1\end{array}\right): p=.243$, $F_{\mathrm{S}}<1.40{ }^{8}$

Cardiovascular reactivity checks. Following Experiment 2, we calculated mean scores for HR, PEP, CO, and TPR for baseline and speech, then reactivity scores (subtracting baseline from speech scores), the TCI (indicating relative challenge), and checked data for outliers (none were identified).

Task engagement. We first checked whether the speech task was actively engaging. Indeed, HR reactivity increased from baseline to speech, $t(53)=6.36, p<.001, M D=7.15$, $95 \% \mathrm{CI}=[4.89,9.40]$, whereas PEP reactivity decreased, $t(53)=-2.43, p=.019, M D=-3.56,95 \% \mathrm{CI}=[-6.50$, $-0.62]$. Accordingly, the speech constituted motivated performance for which relative challenge could be assessed. 
Across conditions, there was a slight (significant) increase in $\mathrm{CO}, t(53)=2.80, p=.007, M D=0.06,95 \% \mathrm{CI}=[0.02$, $0.10]$, and a strong increase in TPR, $t(53)=5.21, p<.001$, $M D=516.17,95 \% \mathrm{CI}=[317.35,714.98]$ (see Supplemental Material). Thus, the current context elicited overall threat (rather than challenge) as basic response.

Cardiovascular threat and challenge. We predicted that highpower-as-opportunity would elicit relatively more challenge - as indicated by higher CO reactivity, higher TCI, and lower TPR reactivity - than high-power-as-responsibility and potentially similar to standard high power. Again, orthogonal contrasts tested these specific predictions, with the focal contrast $\left(\begin{array}{lll}1 & -2 & 1\end{array}\right)$ and residual contrast $\left(\begin{array}{lll}-1 & 0 & 1\end{array}\right)$, comparing opportunity versus responsibility versus standard. Speech preparation time was not logged; thus, it could not serve as covariate.

As expected, $\mathrm{CO}$ reactivity tended to be higher for highpower-as-opportunity $(M=0.11, S E=0.03)$ than highpower-as-responsibility $(M=0.004, S E=0.03)$, as did standard high power $(M=0.06, S E=0.04)$, focal contrast: $F(1,51)=3.18, p=.081, \eta_{p}^{2}=.059 ; M D=0.077,95 \% \mathrm{CI}=$ $[-0.010,0.163]$. High-power-as-opportunity and standard high power did not differ, residual contrast: $F<1, p=.342$ (Figure 5).

In addition, TPR reactivity tended to be lower in the opportunity $(M=362.85, S E=152.48)$ than in the responsibility condition $(M=779.24, S E=164.07)$, as did standard high power $(M=391.15, S E=198.36)$, focal contrast: $F(1,51)=$ $3.80, p=.057, \eta_{p}^{2}=.069, M D=402.24,95 \% \mathrm{CI}=[-11.970$, 816.444]. High-power-as-opportunity and standard high power did not differ, residual contrast: $F<1, p=.910$.

Results for relative challenge (TCI) demonstrated that high-power-as-opportunity $(M=0.52, S E=0.37)$ evoked more challenge than high-power-as-responsibility $(M=$ $-0.71, S E=0.40)$, as did standard high power $(M=0.16, S D$ $=0.49)$, focal contrast: $F(1,51)=4.33, p=.043, \eta_{p}^{2}=.078$, $M D=1.054,95 \% \mathrm{CI}=[0.037,2.070]$. Again, challenge was similar in the opportunity and the standard condition, $F<1$, $p=.554$ (Figure 6).

\section{Discussion}

Supporting our predictions with physiological indicators, power-holders exhibited relatively less challenge (and more threat) when construing power as responsibility, rather than as an opportunity or simply having "standard" high power (without construing power in a specific way). This extends results from Experiment 2 by means of highly standardized roles in a realistic role-play and an identical task across conditions which tended to, generally, induce threat (rather than challenge as in Experiment 2). Including "standard" high power suggests that construal as responsibility may have driven the effect; yet, due to our small sample in the control condition, this remains tentative.

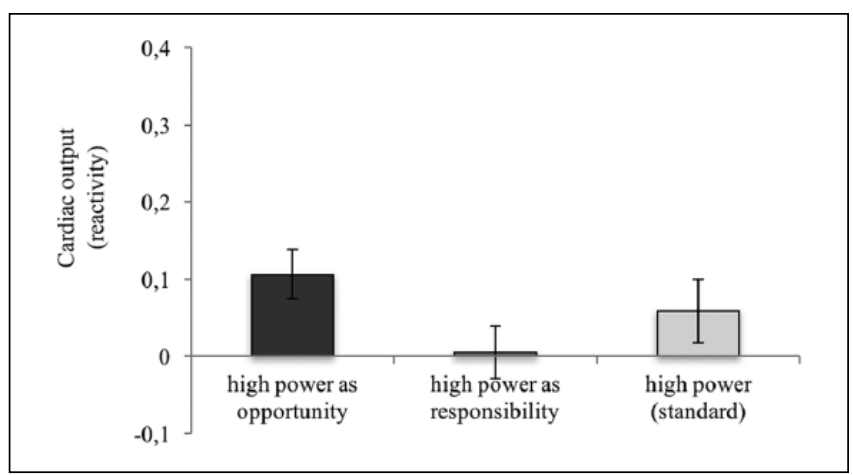

Figure 5. Cardiac output reactivity (changes for speech over baseline) as a function of Construal of high power (Experiment 2, $n=54)$.

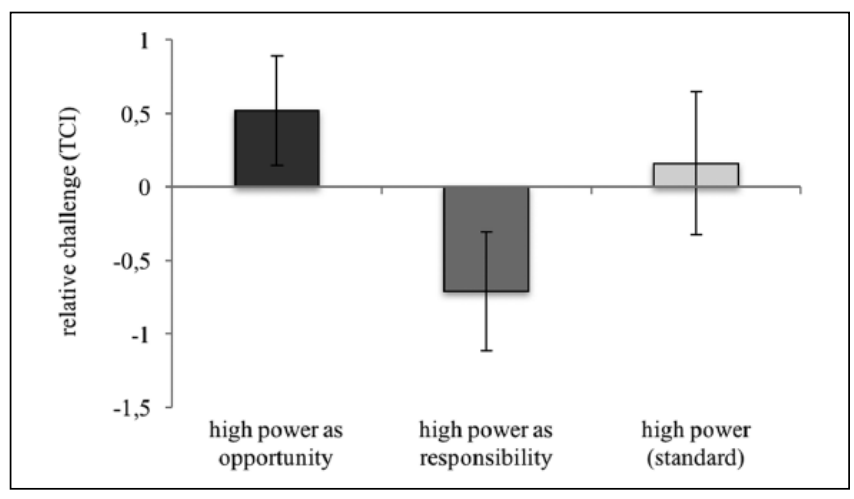

Figure 6. Relative challenge (higher values indicate relatively more challenge; lower values indicate relatively more threat) as a function of Construal of high power (Experiment 2, $n=54$ ). Note. $\mathrm{TCl}=$ threat-challenge index.

\section{Meta-Analysis Across Appraisals and Physiological Indicators}

Experiments 2 and 3 used smaller samples than ideal to ensure high statistical power. To assess the robustness of findings, we thus conducted a meta-analysis on the effect of high-power-as-responsibility versus high-power-as-opportunity across studies - as these represent the two crucial conditions we had implemented in all studies and, thus, could combine. To this end, we calculated the mean effect size $r$, weighed for sample size, for (a) the effects on relative challenge combined for Experiments $1 \mathrm{a}$ and $1 \mathrm{~b}$ and $(\mathrm{b})$ the effects on $\mathrm{CO}$ reactivity, TPR reactivity, and TCI combined for Experiments 2 and 3 (Table 1).

Importantly, effects for high-power-as-responsibility versus high-power-as-opportunity were significant with mean effect sizes between $.22 \leq r \leq .27$ across outcomesexcept for TPR reactivity, whose marginal effect needs to be interpreted with caution. With this one exception, analyses across studies show that high-power-as-responsibility did elicit less (subjective and physiological) challenge than high-power-as-opportunity. 
Table I. Meta-Analytical Results Comparing the Effects of High-Power-as-Opportunity Versus High-Power-as-Responsibility Across Experiments $\mathrm{I} a$ and $\mathrm{I} b$ and Across Experiments 2 and 3.

\begin{tabular}{|c|c|c|c|}
\hline & $r$ (effect size) & $p$ & $95 \% \mathrm{Cl}$ \\
\hline \multicolumn{4}{|l|}{ Experiments $\mathrm{I} a$ and $\mathrm{I} b$} \\
\hline Relative challenge (self-rated) & $.22 * * * *$ & $<.001$ & {$[0.1901,0.2422]$} \\
\hline \multicolumn{4}{|c|}{ Experiments 2 and 3 (no covariates included) } \\
\hline CO reactivity & $.27^{* *}$ & .005 & {$[0.0603,0.4487]$} \\
\hline TPR reactivity & $.16^{\dagger}$ & .059 & {$[-0.0459,0.3599]$} \\
\hline relative challenge $(\mathrm{TCl})$ & $.24 * *$ & .009 & {$[0.0381,0.4308]$} \\
\hline
\end{tabular}

Note. $95 \% \mathrm{Cl}=$ confidence interval for effect size $r ; \mathrm{CO}=$ cardiac output; TPR = total peripheral resistance; $\mathrm{TCl}=$ threat-challenge index from cardiovascular measures.

${ }^{\dagger} p<.10 . * * p<.01 . * * * p<.001$

\section{General Discussion}

Coveting a high-power position can benefit the way how people regulate behavior (Guinote, 2007b) and respond to stressful situations (Akinola \& Mendes, 2014; Scheepers et al., 2012). Yet, at times, high power may be rather taxing, implying potential health hazards (e.g., Galinsky et al., 2015; Sapolsky, 2005). Relatively little attention has been directed to drawbacks of power for the functioning of those who possess it, especially with regard to how power-holders understand their power. To address this, the present work investigated if the construal of power changes psychological and physiological functioning. We proposed that, in straining situations, high power construed as responsibility (rather than as opportunity) may imply a "burden"-namely, such a construal may reduce the (typically effective) higher challenge and lower threat response among power-holders (Akinola \& Mendes, 2014; Scheepers et al., 2012).

Four studies supported this. When power-holders construed power as responsibility, rather than opportunity, they perceived less challenge (see Supplemental Material, for additional results among leaders) and showed cardiovascular responses indicative of less challenge. As methodological strengths, we applied subjective and physiological indicators across assigned roles (Experiments $1 \mathrm{a}$ and 1b), real-life experiences (Experiment 2), standardized role-play (Experiment 3), and different motivated performance situations; this underlines the validity of findings. Notably, absolute threat and challenge patterns differed between Experiments 2 (overall challenge) and 3 (overall threat). Still, both studies yielded the expected relative differences between high-power-as-responsibility and high-power-asopportunity. This suggests that construal of high power likely alters threat-challenge responses even under different baseline conditions. Our meta-analysis further substantiated our hypothesis.

Importantly, Experiment 1a demonstrated that these effects of construal occur for those high in power (but produced an opposite effect for those low in power). This suggests that it is the construal of high power (and not of any other role) as opportunity/responsibility resulting in these effects. Moreover, construal affected responses to the intelligence test (Experiment 1b) as a task completely unrelated to power. Still, depending on which construal was induced, power-holders experienced this test as relatively more or less challenging. First, this study rules out potential demand effects. Second, this result suggests that, just as the experience of high versus low power can carry over to other contexts (Smith \& Galinsky, 2010), also the mere construal of power - understanding one and the same powerful position as responsibility (vs. opportunity) - can change responses to an unrelated situation. Future research could examine if this may be driven by an increased awareness of demands, carrying over across contexts.

\section{Implications for Research and Practice}

The results have implications for power research. High (vs. low) power facilitates challenge (Akinola \& Mendes, 2014; Scheepers et al., 2012), though personal and structural factors can limit these benefits (Josephs et al., 2006; Sapolsky, 2005). Our research shows that this more effective pattern among power-holders is, in fact, qualified by how powerholders (are led to) construe their power. The advantages of high power are mitigated when understanding this position as responsibility, rather than as opportunity.

In fact, power-holders construing power as responsibility revealed a physiological pattern suggestive of a "burden" of power. Moreover, high-power-as-responsibility produced a (low) challenge response pattern somewhat similar to those low in power in Experiments $1 \mathrm{~b}$ and 2 - even though the perceived level of power (i.e., outcome control) between construal conditions did not differ. It may well be that construal alters other stress-buffering effects of power, beyond the cardiovascular patterns investigated here, such as hormonal reactions (Akinola \& Mendes, 2014), well-being (Kifer et al., 2013), or performance boosts under pressure (Kang, Galinsky, Kray, \& Shirako, 2015; Schmid \& Mast, 2013). This remains an avenue for future studies.

Given these findings, one may wonder which construal drives the effects. Experiment 3 suggests that it could be responsibility - in other words, that opportunity might be the 
likely "standard" construal of high power. This conclusion remains tentative, however, due to our small sample. Supporting this idea, established threat-challenge results for "standard" high power (Akinola \& Mendes, 2014; Scheepers et al., 2012) seem more similar to our high-power-as-opportunity condition. Moreover, opportunity appears to be the likely default construal of power in Western cultures (Torelli \& Shavitt, 2010). Yet, even within one culture, people can construe "standard" high power differently, depending on traits (e.g., Chen et al., 2001; Côté et al., 2011; Gordon \& Chen, 2013) or situational factors (Scholl, Moeller, et al., 2017; Scholl, Sassenberg, et al., 2017). Taken together, if a person who receives power will understand this power as an opportunity or as a responsibility likely depends on the context and on this specific person.

From a practical point of view, leaders considering power as an opportunity may act in more selfish ways potentially undermining subordinates' performance (Chen et al., 2001; Sassenberg et al., 2014). Accordingly, power-holders acknowledging responsibility are likely to boost organizational success and subordinates' satisfaction (De Hoogh \& Den Hartog, 2008). However, the present data suggest that, beyond these benefits for others, becoming aware of one's responsibility may come at costs for power-holders. This seems to create a tension: The type of leadership that benefits organizations may burden the power-holder. To resolve this, power-holders construing power as responsibility might, in the long run, get used to their responsibilities and develop more supportive relations with subordinates - both of which may help power-holders cope with demands and, thereby, mitigate drawbacks of responsibility. Offering power-holders support in resolving this tension could be one way toward responsible, sustainable leadership.

To conclude, high power provides not only an opportunity to "get things done" but also responsibility to take care of things. High power can, in principle, facilitate effective functioning in stressful situations. Yet, these benefits seem specific to construing high power as opportunity, rather than responsibility. Those having power may, thus, need to learn how to deal with responsibilities to ensure their own well-being over time.

\section{Acknowledgments}

The authors thank Maryke Hofman, Suzanne Kuiper, and Iris Nagelhout for their help in collecting data for Experiments 2 and 3.

\section{Declaration of Conflicting Interests}

The author(s) declared no potential conflicts of interest with respect to the research, authorship, and/or publication of this article.

\section{Funding}

The author(s) disclosed receipt of the following financial support for the research, authorship, and/or publication of this article: The authors thank ESCON for supporting Experiment 2 by means of a short visit grant; this project was further supported by a fellowship granted to the first author by the European Social Fund and by the Ministry of Science, Research, and the Arts, Baden-Württemberg.

\section{Notes}

1. In between manipulations and dependent variables (DVs), other factors were manipulated for other studies; these did not significantly alter our effects. When collecting these data, we originally did not intend to test this prediction; for this reason, Experiments 1a, 2, and 3 directly tested our predictions with similar measures or more objective indicators.

2. We also assessed opportunity (e.g., "As part of my role, I can follow my own ideas"; five items, $\alpha=.88$ ) and social responsibility (e.g., "I am concerned how my actions impact others"; five items, $\alpha=.89$ ) after several filler tasks to explore relative responsibility (i.e., combining responsibility- and recoded opportunity-items)$M_{\text {high-power-as-responsibility }}=0.27, S D=1.19 ; M_{\text {high-power-as-opportunity }}=$ $-0.22, S D=1.08, t(89)=2.06, p=.043, d=.43$.

3 . The original sample comprised $n=89(n=29$ or 30 per condition); due to technical measurement errors, usable cardiovascular data were only obtained for $n=81$ reported here.

4. We also explored resources/demands, self- or other-focus, mood, and closeness to the other person(s).

5. $n=1$ is missing because the speech recording was unusable.

6. Results for cardiac output (CO) reactivity were similar without covariate $\left(M_{\text {low power }}=0.57, S E=0.19 ; M_{\text {responsibility }}=0.54, S E\right.$ $\left.=0.20 ; M_{\text {opportunity }}=1.11, S E=0.21\right)$, focal contrast: $p=.029$, residual contrast: $p=.909$. Also, the pattern for total peripheral resistance (TPR) was similar without covariate. Results for threat-challenge index (TCI) are similar but weaker without covariate $\left(M_{\text {low power }}=-0.20, S E=0.29 ; M_{\text {high-power-as-responsibility }}=\right.$ $-0.20, S E=0.32 ; M_{\text {high-power-as-opportunity }}=0.44, S E=0.32$ ), focal contrast: $p=.102$, residual contrast: $p=.993$.

7. The original sample comprised $n=75$ ( $n=25$ per condition); due to technical measurement errors or procedural problems (failures to deliver a speech), only $n=54$ provided usable cardiovascular data. Advice-taking results from this study are reported in a separate paper; see De Wit, Scheepers, Ellemers, Sassenberg, and Scholl (2017).

8. We explored responsibility/opportunity ("My position felt like a responsibility/opportunity") with four items to predict relative responsibility (combining responsibility- and recoded opportunity-items); $M_{\text {high-power-as-responsibility }}=4.68, S E=0.15 ; M_{\text {high-power- }}$ as-opportunity $=4.23, S E=0.14 ; M_{\text {high-power-standard }}=4.44, S E=0.18$, focal contrast $(-211): p=.074$, residual contrast $(0-11): p=$ .359. A pretest with a non-overlapping sample $(n=98)$ confirmed that construal did not change subjectively experienced power in a high-power role as implemented in Experiment 3: High-power construal neither altered feelings of power $\left(M_{\text {opportunity }}=5.53\right.$, $S D=0.72 ; M_{\text {responsibility }}=5.50, S D=0.98 ; M_{\text {standard }}=5.38, S D=$ $0.86), F<1$, nor perceived power $\left(M_{\text {opportunity }}=5.98, S D=0.83\right.$; $\left.M_{\text {responsibility }}=6.16, S D=0.87 ; M_{\text {standard }}=6.12, S D=0.76\right), F<$ 1 ; both measures were highly correlated, $r(98)=.63, p<.001$. Importantly, this shows that our effects on challenge very likely do not result from any changes in subjectively experienced power between construal conditions.

\section{Supplemental Material}

Supplementary material is available online with this article. 


\section{References}

Abelson, R. P., \& Prentice, D. A. (1997). Contrast tests of interaction hypothesis. Psychological Methods, 2, 315-328.

Akinola, M., \& Mendes, W. B. (2014). It's good to be the king: Neurobiological benefits of higher social standing. Social Psychological and Personality Science, 5, 43-51.

Anderson, C., \& Galinsky, A. D. (2006). Power, optimism, and risktaking. European Journal of Social Psychology, 36, 511-536.

Blascovich, J. (2008). Challenge, threat, and health. In J. Y. Shah \& W. L. Gardner (Eds.), Handbook of motivation science (pp. 481-493). New York, NY: Guilford Press.

Blascovich, J., Seery, M. D., Mugridge, C. A., Norris, R. K., \& Weisbuch, M. (2004). Predicting athletic performance from cardiovascular indexes of challenge and threat. Journal of Experimental Social Psychology, 40, 683-688.

Blascovich, J., \& Tomaka, J. (1996). The biopsychosocial model of arousal regulation. In M. Zanna (Ed.), Advances in experimental social psychology (Vol. 28, pp. 1-51). New York, NY: Academic Press.

Byrne, A., Dionisi, A. M., Barling, J., Akers, A., Robertson, J., Lys, R., \& Dupré, K. (2014). The depleted leader: The influence of leaders' diminished psychological resources on leadership behaviors. The Leadership Quarterly, 25, 344-357.

Chen, S., Lee-Chai, A. Y., \& Bargh, J. A. (2001). Relationship orientation as a moderator of the effects of social power. Journal of Personality and Social Psychology, 80, 173-187.

Côté, S., Kraus, M. W., Cheng, B. H., Oveis, C., van der Löwe, I., Lian, H., \& Keltner, D. (2011). Social power facilitates the effect of prosocial orientation on empathic accuracy. Journal of Personality and Social Psychology, 101, 217-232. doi:10.1037/a0023171

De Hoogh, A. H. B., \& Den Hartog, D. N. (2008). Ethical and despotic leadership, relationships with leader's social responsibility, top management team effectiveness and subordinates' optimism: A multi-method study. The Leadership Quarterly, 19, 297-311.

De Wit, F., Scheepers, D., Ellemers, N., Sassenberg, K., \& Scholl, A. (2017). Whether power holders construe their power as responsibility or opportunity influences their tendency to take advice from others. Journal of Organizational Behavior, 38 , 923-949.

Eeftinck Schattenkerk, D. W., van Lieshout, J. J., van den Meiracker, A. H., Wesseling, K. R., Blanc, S., Wieling, W., ... Westerhof, B. E. (2009). Nexfin noninvasive continuous blood pressure validated against Riva-Rocci/Korotkoff. American Journal of Hypertension, 22, 378-383. doi:10.1038/ajh.2008.368

Fast, N. J., Gruenfeld, D. H., Sivanathan, N., \& Galinsky, A. D. (2009). Illusory control: A generative force behind power's far-reaching effects. Psychological Science, 20, 502-508.

Faul, F., Erdfelder, E., Lang, A.-G., \& Buchner, A. (2007). G*Power 3: A flexible statistical power analysis program for the social, behavioral, and biomedical sciences. Behavior Research Methods, 39, 175-191.

Fiske, S. T., \& Berdahl, J. (2007). Social power. In A. W. Kruglanski \& E. T. Higgins (Eds.), Social psychology: Handbook of basic principles (2nd ed., pp. 678-692). New York, NY: Guilford Press.

Galinsky, A. D., Gruenfeld, D. H., \& Magee, J. C. (2003). From power to action. Journal of Personality and Social Psychology, $85,453-466$.
Galinsky, A. D., Rucker, D. R. D., \& Magee, J. C. (2015). Power: Past findings, present considerations, and future directions. In J. Simpson (Assoc. Ed.),M. Mikulincer \& P. Shaver (Eds.), APA handbook of personality and social psychology, Vol. 3: Interpersonal relationships (pp. 421-460). Washington, DC: American Psychological Association.

Gordon, A. M., \& Chen, S. (2013). Does power help or hurt? The moderating role of self-other focus on power and perspective-taking in romantic relationships. Personality and Social Psychology Bulletin, 39, 1097-1110.

Guinote, A. (2007a). Power affects basic cognition: Increased attentional inhibition and flexibility. Journal of Experimental Social Psychology, 43, 685-697.

Guinote, A. (2007b). Power and goal pursuit. Personality and Social Psychology Bulletin, 33, 1076-1087.

Hayes, A. F. (2013). Introduction to mediation, moderation, and conditional process analysis. New York, NY: Guilford Press.

Josephs, R. A., Sellers, J. G., Newman, M. L., \& Mehta, P. H. (2006). The mismatch effect: When testosterone and status are at odds. Journal of Personality and Social Psychology, 90, 999-1013.

Kang, S. K., Galinsky, A. D., Kray, L. J., \& Shirako, A. (2015). Power affects performance when the pressure is on: Evidence for low-power threat and high-power lift. Personality and Social Psychology Bulletin, 41, 726-735.

Keltner, D., Gruenfeld, D. H., \& Anderson, C. (2003). Power, approach, and inhibition. Psychological Review, 110, 265-284.

Kifer, Y., Heller, D., Perunovic, W. Q. E., \& Galinsky, A. D. (2013). The good life of the powerful: The experience of power and authenticity enhances subjective well-being. Psychological Science, 24, 280-288.

Mehta, P. H., \& Josephs, R. A. (2010). Testosterone and cortisol jointly regulate dominance: Evidence for a dual-hormone hypothesis. Hormones and Behavior, 58, 898-906.

Mendes, W. B., Blascovich, J., Hunter, S. B., Lickel, B., \& Jost, J. T. (2007). Threatened by the unexpected: Physiological responses during social interactions with expectancy-violating partners. Journal of Personality and Social Psychology, 92, 698-716.

Mendes, W. B., Blascovich, J., Major, B., \& Seery, M. (2001). Challenge and threat responses during downward and upward social comparisons. European Journal of Social Psychology, 31, 477-497.

Myers, J. L., \& Well, A. D. (1995). Research design and statistical analysis. Hillsdale, NJ: Lawrence Erlbaum.

Neter, J., Kutner, M. H., Nachtsheim, C. J., \& Wasserman, W. (1996). Applied linear statistical models (4th ed.). Chicago, IL: Irwin.

Niedenthal, P. M., Brauer, M., Robin, L., \& Innes-Ker, A. H. (2002). Adult attachment and the perception of facial expression of emotion. Journal of Personality and Social Psychology, $82,419-433$.

Overbeck, J. R., \& Park, B. (2006). Powerful perceivers, powerless objects: Flexibility of powerholders' social attention. Organizational Behavior and Human Decision Processes, 99, 227-243.

Peacock, E. J., \& Wong, P. T. (1990). The Stress Appraisal Measure (SAM): A multidimensional approach to cognitive appraisal. Stress Medicine, 6, 227-236.

Roesch, S. C., \& Rowley, A. A. (2005). Evaluating and developing a multidimensional, dispositional measure of appraisal. Journal of Personality Assessment, 85, 188-196. 
Sapolsky, R. M. (2005). The influence of social hierarchy on primate health. Science, 308, 648-653.

Sassenberg, K., Ellemers, N., \& Scheepers, D. (2012). The attraction of social power: The influence of construing power as opportunity versus responsibility. Journal of Experimental Social Psychology, 48, 550-555.

Sassenberg, K., Ellemers, N., Scheepers, D., \& Scholl, A. (2014). "Power corrupts" revisited: The role of construal of power as opportunity or responsibility. In J.-W. van Prooijen \& P. A. M. van Lange (Eds.), Power, politics, and paranoia: Why people are suspicious of their leaders (pp. 73-87). Cambridge, UK: Cambridge University Press.

Scheepers, D., de Wit, F., Ellemers, N., \& Sassenberg, K. (2012). Social power makes the heart work more efficiently: Evidence from cardiovascular markers of challenge and threat. Journal of Experimental Social Psychology, 48, 371-374.

Scheepers, D., Röell, C., \& Ellemers, N. (2015), Unstable power threatens the powerful and challenges the powerless: Evidence from cardiovascular markers of motivation. Frontiers in Psychology, 6, e720.

Schmid, P. C., \& Mast, M. S. (2013). Power increases performance in a social evaluation situation as a result of decreased stress responses. European Journal of Social Psychology, 43, 201-211.

Scholl, A., Moeller, K., Scheepers, D., Nuerk, H.-C., \& Sassenberg, K. (2017). Physiological threat responses predict number processing. Psychological Research, 81, 278-288.

Scholl, A., \& Sassenberg, K. (2014). Where could we stand if I had ... ? How social power impacts counterfactual thinking after failure. Journal of Experimental Social Psychology, 53, 51-61.

Scholl, A., Sassenberg, K., Scheepers, D., Ellemers, N., \& de Wit, F. (2017). A matter of focus: Power-holders feel more responsible after adopting a cognitive other-focus, rather than a selffocus. British Journal of Social Psychology, 56, 89-102.

See, K. E., Morrison, E. W., Rothman, N. B., \& Soll, J. B. (2011). The detrimental effects of power on confidence, advice taking, and accuracy. Organizational Behavior and Human Decision Processes, 116, 272-285.
Seery, M. D., Weisbuch, M., Hetenyi, M. A., \& Blascovich, J. (2010). Cardiovascular measures independently predict performance in a university course. Psychophysiology, 47, 535-539.

Sherwood, A., Allen, M. T., Fahrenberg, J., Kelsey, R. M., Lovallo, W. R., \& van Doornen, L. J. (1990). Methodological guidelines for impedance cardiography. Psychophysiology, 27, 1-23.

Smith, P. K., \& Galinsky, A. D. (2010). The nonconscious nature of power: Cues and consequences. Social and Personality Psychology Compass, 4, 918-938.

Smith, P. K., Wigboldus, D. H., \& Dijksterhuis, A. (2008). Abstract thinking increases one's sense of power. Journal of Experimental Social Psychology, 44, 378-385. doi:10.1016/j. jesp.2006.12.005

Sturm, R. E., \& Antonakis, J. (2015). Interpersonal power: A review, critique, and research agenda. Journal of Management, 41, 136-163.

Tomaka, J., Blascovich, J., Kelsey, R. M., \& Leitten, C. L. (1993). Subjective, physiological, and behavioral effects of threat and challenge appraisal. Journal of Personality and Social Psychology, 18, 616-624.

Torelli, C. J., \& Shavitt, S. (2010). Culture and concepts of power. Journal of Personality and Social Psychology, 99, 703-723.

Weick, M., \& Guinote, A. (2010). How long will it take? Power biases time predictions. Journal of Experimental Social Psychology, 46, 595-604.

Weisbuch-Remington, M., Mendes, W. B., Seery, M. D., \& Blascovich, J. (2005). The nonconscious influence of religious symbols in motivated performance situations. Personality and Social Psychology Bulletin, 31, 1203-1216.

Whitson, J. A., Liljenquist, K. A., Galinsky, A. D., Magee, J. C., Gruenfeld, D. H., \& Cadena, B. (2013). The blind leading: Power reduces awareness of constraints. Journal of Experimental Social Psychology, 49, 579-582.

Wirth, M. M., Welsh, K. M., \& Schultheiss, O. C. (2006). Salivary cortisol changes in humans after winning or losing a dominance contest depend on implicit power motivation. Hormones and Behavior, 49, 346-352. 